\title{
Hodgkin lymphoma treatment with ABVD in the US and the EU: neutropenia occurrence and impaired chemotherapy delivery
}

\author{
Matthias Schwenkglenks ${ }^{1 *}$, Ruth Pettengell ${ }^{2}$, Thomas D Szucs', Eva Culakova ${ }^{3}$, Gary H Lyman $^{3}$
}

\begin{abstract}
Background: In newly diagnosed patients with Hodgkin lymphoma $(\mathrm{HL})$ the effect of doxorubicin, bleomycin, vinblastine and dacarbazine (ABVD)-related neutropenia on chemotherapy delivery is poorly documented. The aim of this analysis was to assess the impact of chemotherapy-induced neutropenia (CIN) on ABVD chemotherapy delivery in $\mathrm{HL}$ patients.

Study design: Data from two similarly designed, prospective, observational studies conducted in the US and the EU were analysed. One hundred and fifteen HL patients who started a new course of ABVD during 2002-2005 were included. The primary objective was to document the effect of neutropenic complications on delivery of ABVD chemotherapy in $\mathrm{HL}$ patients. Secondary objectives were to investigate the incidence of CIN and febrile neutropenia (FN) and to compare US and EU practice with ABVD therapy in HL. Pooled data were analysed to explore univariate associations with neutropenic events.

Results: Chemotherapy delivery was suboptimal (with a relative dose intensity $\leq 85 \%$ ) in $18-22 \%$ of patients. The incidence of grade 4 CIN in cycles 1-4 was lower in US patients (US 24\% vs. EU 32\%). Patients in both the US and the EU experienced similar rates of FN across cycles 1-4 (US 12\% vs. EU 11\%). Use of primary colony-stimulating factor (CSF) prophylaxis and of any CSF was more common in the US than the EU (37\% vs. $4 \%$ and $78 \%$ vs. $38 \%$, respectively). The relative risk (RR) of dose delays was 1.54 (95\% confidence interval $[\mathrm{Cl}] 1.08-2.23, p=0.036$ ) for patients with vs. without grade $4 \mathrm{CIN}$ and the RR of grade $4 \mathrm{CIN}$ was 0.35 (95\% Cl 0.12-1.06, $p=0.046)$ for patients with vs. without primary CSF prophylaxis.
\end{abstract}

Conclusions: In this population of HL patients, CIN was frequent and FN occurrence clinically relevant. Chemotherapy delivery was suboptimal. CSF prophylaxis appeared to reduce CIN rates.

\section{Introduction}

Combination therapy with doxorubicin, bleomycin, vinblastine and dacarbazine (ABVD) is the standard chemotherapy regimen for patients with Hodgkin lymphoma (HL) [1-3]. Myelosuppression, in particular neutropenia, is common during ABVD treatment [2]. Chemotherapy-induced neutropenia (CIN) can lead to febrile neutropenia (FN), which is associated with considerable morbidity, mortality and costs [4]. Standard care for the majority of FN patients requires hospitalisation and administration of intravenous antibiotics $[5,6]$.

\footnotetext{
* Correspondence: m.schwenkglenks@unibas.ch

${ }^{1}$ Institute of Pharmaceutical Medicine, University of Basel, Basel, Switzerland Full list of author information is available at the end of the article
}

Neutropenic events often result in dose delays and dose reductions, leading to impaired chemotherapy delivery which has been associated with decreased survival in certain types of cancer [7-10], indicating that optimal intensity of chemotherapy treatment can improve patient outcomes [8]. Colony-stimulating factors (CSFs) have been shown to reduce the incidence and severity of neutropenic events across a broad range of malignancies and regimens and also to support the delivery of full chemotherapy dose intensity $[5,11]$.

In patients with HL, the effect of ABVD-related neutropenia and neutropenic complications on chemotherapy delivery are poorly documented [2,12]. Two similarly designed, prospective, observational studies were conducted in the US [13] and Europe [14] to 
assess the incidence of neutropenia in patients undergoing chemotherapy. Here we present a subgroup analysis of HL patients from these studies. The primary objective was to assess the effects of neutropenic complications on the delivery of ABVD chemotherapy. Secondary objectives were to investigate the incidence of $\mathrm{CIN}$ and FN in patients with HL undergoing ABVD chemotherapy and to compare US and EU practice with ABVD therapy in HL.

\section{Methods}

Two similarly designed, prospective, observational studies $[13,14]$ enrolled patients with solid tumours or lymphoma initiating a new course of chemotherapy, with at least 4 cycles planned, during the period 2002-2005. In the US, a total of 4458 patients were recruited from 115 community practices. In the $\mathrm{EU}$, a total of 749 patients were recruited from 66 clinical centres in Belgium, France, Germany, Spain and the UK.

Patients eligible for inclusion in this subgroup analysis were adults aged $\geq 18$ years about to start a new course of ABVD (patients in whom doxorubicin was replaced with epirubicin were also allowed). In the US study, patients had a minimum life expectancy of at least 3 months. In the EU study, patients had to be HL stage IB-IV. Prior chemotherapy and concurrent radiation therapy were permitted. Key exclusion criteria were: use of antibody-based or cell-based immunotherapies, a history of stem-cell or bone-marrow transplantation and HIV infection. Additionally, the US study excluded patients diagnosed with myeloma or treated for active infection and did not allow participation in double-blind clinical trials. Patients in the EU were excluded if they had conditions causing neutropenia, malignant conditions with myeloid characteristics, or active infection within 72 hours prior to the start of chemotherapy. Concurrent participation in phase I/II clinical trials was not permitted. Ethical approval was obtained for all centres and all participants provided informed consent.

Data were merged and variable definitions reconciled to form a single, pooled dataset. Body surface area was calculated using the Mosteller formula [15]. Delivery of chemotherapy was assessed by considering the proportion of patients that received relative dose intensity (RDI) $\leq 85 \%$ of the planned or standard dose intensity and by documenting the occurrence of dose reductions $>10 \%$ and dose delays $>3$ days. As delivery of vinblastine is unlikely to be affected by neutropenia, this agent was excluded from the calculation of RDI and dose reductions. In the US study, blood counts were drawn at the beginning of each cycle and at mid-cycle, for up to 4 cycles of treatment. In the EU study, a blood count at the expected (protocol defined) absolute neutrophil count (ANC) nadir was required in cycle 1. Centres were also required to record all blood counts taken during each patient's chemotherapy treatment. Grades 3 and $4 \mathrm{CIN}$ were defined as an ANC $<1000 / \mathrm{mm}^{3}$ and $<500 / \mathrm{mm}^{3}$ [16], respectively, and FN as ANC $<1000 /$ $\mathrm{mm}^{3}$ in combination with site-reported fever above $38^{\circ} \mathrm{C}$ and/or infection. Primary CSF prophylaxis was defined as CSF use in the first cycle of chemotherapy before a documented grade 3-4 CIN occurred or denoted as primary prophylaxis by the site.

Due to the limited sample size, analyses were predominantly descriptive. Univariate associations between variables were explored in the pooled dataset. Associations of binary data were expressed as relative risks with accompanying $95 \%$ confidence intervals. Significance testing was based on Fisher's exact test (2-sided) due to small sample size, which explains some apparent inconsistencies between $p$ values and confidence limits.

\section{Results}

\section{Patient characteristics}

A total of $115 \mathrm{HL}$ patients (68 US patients, $47 \mathrm{EU}$ patients) met the eligibility criteria and were included in the analysis. The age range was 19-83 years (median 36) in US patients and 18-74 years (median 34) in EU patients; $49 \%$ of US patients and $38 \%$ of EU patients were female. US patients had slightly higher body surface area and higher incidence of stage III/IV disease than EU patients and were more often pre-treated with radiotherapy (Table 1). Eastern Cooperative Oncology Group performance status was similar between US and EU patients and no patients had prior chemotherapy.

\section{Treatment characteristics}

In most patients, 4-5 or 6 cycles of ABVD were planned. In the US and the EU, median planned dose intensities (expressed on the basis of actual body weight) met the ABVD standard of bleomycin, 5 units $/ \mathrm{m}^{2} /$ week; doxorubicin, $12.5 \mathrm{mg} / \mathrm{m}^{2} /$ week; dacarbazine, $187.5 \mathrm{mg} / \mathrm{m}^{2} /$ week; and vinblastine, $3 \mathrm{mg} / \mathrm{m}^{2} /$ week. Actual planned dose intensities deviated in a number of patients and resulting means were marginally higher in the EU patients (Table 1). One US patient (1.5\%) and three EU patients (6.4\%) received epirubicin instead of doxorubicin (EBVD).

The percentage of patients receiving CSF overall and as primary prophylaxis was higher for US patients (any CSF use: US 78\% vs. EU 38\%; primary CSF prophylaxis: US $37 \%$ vs. EU 4\%). Antibiotic use was similar between the two populations (any antibiotic use: US $41 \%$ vs. EU 49\%; primary prophylaxis with antibiotics: US 13\% vs. EU 17\%).

\section{Chemotherapy delivery}

Dose delays $>3$ days were more frequently observed in EU patients and dose reductions $>10 \%$ were more frequent in US patients (Figure 1). Chemotherapy delivery 
Table 1 Patient, disease and treatment characteristics

\begin{tabular}{|c|c|c|c|}
\hline Characteristic & & US $(\mathrm{N}=68)$ & $\mathrm{EU}(\mathrm{N}=47)$ \\
\hline Age in years, mean \pm SD (range) & & $40.9 \pm 16.2(19-83)$ & $37.9 \pm 16.5(18-74)$ \\
\hline Female gender, $\mathrm{N}(\%)$ & & $33(48.5)$ & $18(38.3)$ \\
\hline \multirow[t]{3}{*}{ Race, N (\%) } & Caucasian/white & $54(79.4)$ & $46(97.9)$ \\
\hline & Black & $10(14.7)$ & $0(0.0)$ \\
\hline & Other & $4(5.9)$ & $1(2.1)$ \\
\hline $\mathrm{BSA}$ at baseline in $\mathrm{m}^{2}$, mean $\pm \mathrm{SD}$ (range) & & $1.94 \pm 0.26(1.42-2.53)$ & $1.85 \pm 0.21(1.41-2.28)$ \\
\hline \multirow[t]{3}{*}{ ECOG status, N (\%) } & 0 & $47(69.1)$ & $30(63.8)$ \\
\hline & 1 & $20(29.4)$ & $14(29.8)$ \\
\hline & 2 & $1(1.5)$ & $3(6.4)$ \\
\hline \multirow[t]{4}{*}{ Disease stage ${ }^{1}, \mathrm{~N}(\%)$} & । & $8(12.1)^{2}$ & $5(10.6)$ \\
\hline & $\|$ & $30(45.5)^{2}$ & $28(59.6)$ \\
\hline & III & $23(34.8)^{2}$ & $8(17.0)$ \\
\hline & IV & $5(7.6)^{2}$ & $6(12.8)$ \\
\hline Prior radiotherapy, N (\%) & & $6(8.8)$ & $0(0.0)$ \\
\hline Baseline WBC in $10^{3} / \mathrm{mm}^{3}$, mean $\pm S D$; median & & $9.4 \pm 4.9 ; 7.8$ & $9.5 \pm 3.8 ; 8.4$ \\
\hline Baseline ANC in $10^{3} / \mathrm{mm}^{3}$, mean $\pm \mathrm{SD}$; median & & $6.5 \pm 3.3 ; 5.3^{2}$ & $7.2 \pm 3.6 ; 6.6$ \\
\hline Diabetes, N (\%) & & $8(11.8)$ & $0(0.0)$ \\
\hline Cardiac comorbidity, N (\%) & & $0(0.0)$ & $2(4.3)$ \\
\hline \multicolumn{4}{|c|}{ Planned dose intensity in $\mathrm{mg} / \mathrm{m}^{2} /$ week, mean $\pm \mathrm{SD}$; median } \\
\hline Bleomycin & & $4.9 \pm 0.9 ; 4.9$ & $5.3 \pm 1.2 ; 5.0$ \\
\hline Doxorubicin & & $12.5 \pm 1.9 ; 12.3$ & $12.8 \pm 2.7 ; 12.4^{3}$ \\
\hline Dacarbazine & & $184.0 \pm 29.5 ; 183.6$ & $198.3 \pm 50.2 ; 186.7$ \\
\hline Vinblastine & & $3.0 \pm 0.5 ; 2.9$ & $3.2 \pm 0.8 ; 3.0$ \\
\hline \multirow[t]{4}{*}{ Planned cycle number, N (\%) } & $\leq 3$ & $0(0.0)$ & $2(4.3)$ \\
\hline & $4-5$ & $29(42.6)$ & $16(34.0)$ \\
\hline & 6 & $38(55.9)$ & $26(55.3)$ \\
\hline & $\geq 8$ & $1(1.5)$ & $3(6.4)$ \\
\hline \multirow[t]{3}{*}{ Planned cycle length in days, N (\%) } & 14 & $7(10.3)$ & $5(10.6)$ \\
\hline & 21 & $5(7.4)$ & $2(4.3)$ \\
\hline & 28 & $56(82.4)$ & $40(85.1)$ \\
\hline
\end{tabular}

$B S A$ body surface area; ECOG Eastern Cooperative Oncology Group; WBC white blood cell count; $A N C$ absolute neutrophil count.

${ }^{1}$ US: based on American Joint Committee Cancer staging; EU: based on Ann Arbor staging.

${ }^{2} \mathrm{~N}=66$ due to missing values.

${ }^{3} \mathrm{~N}=44$ as 3 EU patients received epirubicin.

was suboptimal in $18-22 \%$ of patients (RDI $\leq 85 \%$ of ABVD standard). Comparison against the actual planned dose intensity for each individual patient led to a very similar result.

\section{Incidence of neutropenia and FN}

Patients in both the US and the EU experienced similar rates of FN in the first cycle of chemotherapy (US 7\% vs. EU $9 \% \mathrm{EU}$ ) and across cycles $1-4$ (US $12 \%$ vs. EU $11 \%)$. The incidence of CIN in cycles 1-4 was lower in US patients (Figure 2). US patients had a mean ANC nadir of $2000 \pm 2300 / \mathrm{mm}^{3}$ in the first cycle compared to EU patients whose mean ANC nadir was $1300 \pm$ $1000 / \mathrm{mm}^{3}$ in the first cycle.
Factors associated with chemotherapy delivery in the pooled dataset

The relative risk (RR) of dose delays $>3$ days was 1.54 (95\% confidence interval [CI] 1.08-2.23, $p=$ 0.036 ) for patients with vs. without grade 4 CIN. There was no evidence of an association between the presence of grade 4 CIN in any cycle and dose reductions $>10 \%$ or RDI $\leq 85 \%$ of planned/standard. Similarly, there was no evidence of an association between grade 4 CIN in cycle 1 and dose delays, dose reductions or RDI $\leq 85 \%$ of planned/standard. CSF primary prophylaxis was not associated with dose delays $>3$ days, dose reduction $>10 \%$ or RDI $\leq 85 \%$ of planned/ standard. 


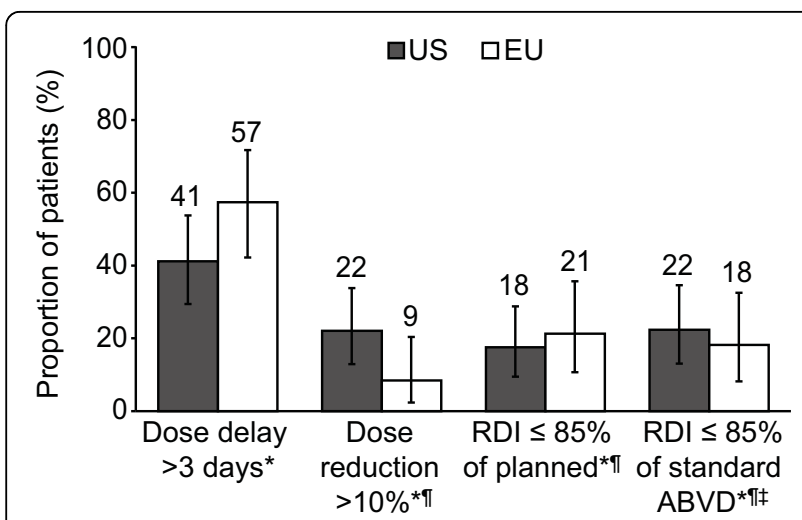

Figure 1 Chemotherapy delivery in US and EU patients. Incidence of dose delays $>3$ days in any cycle, dose reductions $>$ $10 \%$ in any drug in any cycle, and $\mathrm{RDI} \leq 85 \%$ compared to either planned RDI or standard ABVD in US $(N=68)$ and EU $(N=47)$ patients during the first 4 cycles of chemotherapy. Error bars represent 95\% Cls. *Assessment took into account administered cycles only; "Disregarding vinblastine; ${ }^{\ddagger} E B V D$ patients excluded (US $\mathrm{N}=67$, EU N = 44); Standard ABVD: bleomycin 5 units $/ \mathrm{m}^{2} /$ week, doxorubicin $12.5 \mathrm{mg} / \mathrm{m}^{2} /$ week, dacarbazine $187.5 \mathrm{mg} / \mathrm{m}^{2} /$ week, vinblastine $3 \mathrm{mg} / \mathrm{m}^{2} /$ week. $R D /$ relative dose intensity; $A B V D$ doxorubicin, bleomycin, vinblastine and dacarbazine; $C /$ confidence interval; EBVD epirubicin, bleomycin, vinblastine and dacarbazine.

Association of CSF prophylaxis and neutropenic events in the pooled dataset

Patients receiving CSF primary prophylaxis were less likely to develop CIN than patients who did not receive CSF primary prophylaxis. The RR of grade $4 \mathrm{CIN}$ in any cycle was 0.35 (95\% CI 0.12-1.06, $p=0.046$ ) for patients with vs. without primary CSF prophylaxis, and the RR of grade 3 or 4 CIN in any cycle was 0.42 (95\% CI 0.23 $0.76, p<0.001)$. There was also a reduced risk of grade 3 or 4 CIN in cycle 1 for patients with vs. without CSF prophylaxis (RR $0.40,95 \%$ CI $0.19-0.83, p=0.004$ ).

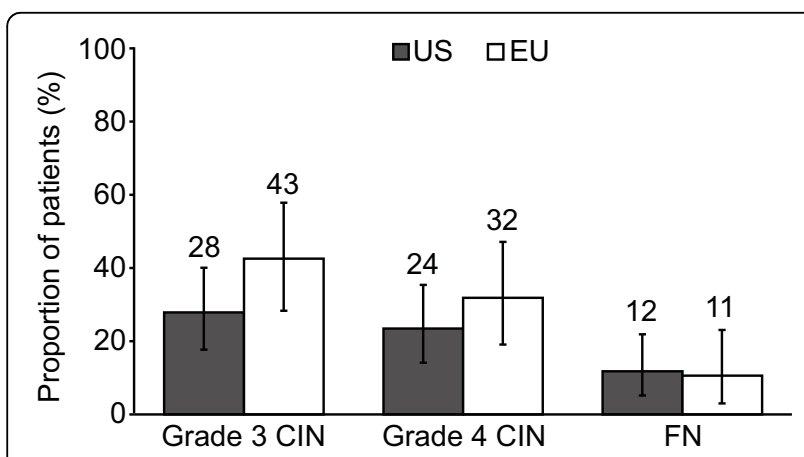

Figure 2 Incidence of neutropenic events in US and EU patients. Incidence of grade 3 and 4 CIN and FN in US ( $N=68)$ and $E U(N=47)$ patients during the first 4 cycles of chemotherapy. Patients with grade $4 \mathrm{CIN}$ were not counted as having grade $3 \mathrm{CIN}$. Error bars represent 95\% Cls. CIN chemotherapy-induced neutropenia; FN febrile neutropenia; Cl confidence interval.
There was no evidence of an association between CSF primary prophylaxis and incidence of $\mathrm{FN}$ in cycle 1 or cycles 1-4. In cycle 1, FN incidence was $7 \%$ in 27 patients with CSF primary prophylaxis and $8 \%$ in 88 patients with no CSF primary prophylaxis (RR 0.93, 95\% CI $0.21-4.22, p=1.000)$. In cycles $1-4$, corresponding incidences were $15 \%$ and $10 \%$ (RR 1.45 , 95\% CI 0.48 $4.33, p=0.500)$. The other univariate associations considered were not statistically significant.

\section{Discussion}

This study assessed the impact of CIN on ABVD chemotherapy delivery in HL patients in the EU and the US. Baseline characteristics were similar in both groups although US patients had a more advanced disease state. In both EU and US patients, CIN occurrence was substantial and the observed FN incidence of $11-12 \%$ was considerably higher than the $4 \%$ reported in current European Organisation for Research and Treatment of Cancer (EORTC) guidelines [5]. EORTC guidelines are based on a literature review of clinical trial data and under-reporting of febrile events has been noted to be common in randomised controlled trials [17]. This study is the first multi-centre investigation of neutropenic event incidence in general populations of $\mathrm{HL}$ patients treated with ABVD. Three retrospective singlecentre studies have also addressed this topic [18-20]. Populations studied were similar to ours with respect to median age and grade $3 / 4 \mathrm{CIN}$ risk per patient. However, grade $3 / 4$ CIN risk per patient was not available from Evens et al. [18], and in the single-physician experience (with no CSF use) reported by Boleti and Mead, the proportion of stage III-IV patients was only $13 \%$ [19]. Overall FN incidence was 10\%, 5-9\% and 5\% in the studies by Chand et al. $(\mathrm{N}=81)$ [20], Evens et al. $(\mathrm{N}=84)$ [18] and Boleti and Mead $(\mathrm{N}=38)$ [19], respectively. These findings are not incompatible with our results, considering that retrospective data may be affected by incomplete recording. In addition, practice patterns can differ, and chance effects may play a role in small patient samples.

In both the US and EU populations, chemotherapy delivery was suboptimal with $18-22 \%$ of patients receiving RDI $\leq 85 \%$ compared to standard/planned. As the importance of ABVD dose intensity in determining remission and survival has not yet been defined [2], the clinical impact of this suboptimal ABVD delivery is not known. However, the data highlight that impaired chemotherapy delivery remains a problem in everyday clinical practice, although single centres may achieve very high average chemotherapy dose intensity [18]. Univariate analysis showed that grade 4 CIN increased the risk of dose delays > 3 days; however, the small patient numbers in each data set did not allow for efficient 
multivariate adjustment to assess the link between neutropenia and compromised chemotherapy delivery. Moreover, due to incomplete timing information, we could not clearly establish which dose delays and dose reductions occurred before or after neutropenic events, which may have diluted some associations. The influence of reduced or delayed chemotherapy delivery on neutropenic event occurrence remains to be assessed in HL patients receiving ABVD.

Use of primary CSF prophylaxis in ABVD patients was more common in the US than the EU, and in the univariate analysis performed, CSF prophylaxis was associated with a reduced risk of grade 4 CIN. However, the numbers of patients in each dataset were too small for efficient multivariate analysis of CIN risk. Despite greater CSF use and more dose reductions in the US population, similar FN rates were observed between patients in the EU and the US. This may be explained by a more advanced disease state in US patients, which has been identified as an adverse risk factor for increased incidence of FN [5].

In summary, CIN was frequent and FN occurrence clinically relevant in HL patients receiving ABVD chemotherapy. Dose delays and dose reductions were frequent and resulted in suboptimal delivery of chemotherapy in approximately one fifth of patients. Use of primary CSF prophylaxis was more common in the US than the EU and appeared to reduce CIN rates.

\section{Acknowledgements}

The authors wish to thank Amgen (Europe) $\mathrm{GmbH}$ for supporting this analysis by an educational grant, and medcept Itd, Switzerland, who provided medical writing support on behalf of Amgen (Europe) $\mathrm{GmbH}$. The INC-EU Study Group is supported by an educational grant from Amgen (Europe) $\mathrm{GmbH}$ and the ANC Study Group by a research grant from Amgen Inc. The authors are responsible for the collection, analysis and interpretation of data, and for the decision to publish.

\section{Author details}

${ }^{1}$ Institute of Pharmaceutical Medicine, University of Basel, Basel, Switzerland ${ }^{2}$ St George's University of London, London, UK. ${ }^{3}$ Duke University, Durham, North Carolina, USA.

\section{Authors' contributions}

RP, MS and TDS were involved in the collection and interpretation of INC-EU prospective study data. EC and GHL were involved in the collection and interpretation of ANC prospective study data. MS performed the data analysis presented here. RP, MS, TDS, EC and GHL participated in drafting the manuscript. All authors read and approved the final manuscript.

\section{Authors Information}

MS, RP, and TDS: On behalf of the Impact of Neutropenia in Chemotherapy - European Study Group (INC-EU).

EC and GHL: On behalf of the Awareness of Neutropenia in Chemotherapy Study Group (ANC)

\section{Competing interests}

RP has received honoraria from Amgen, Bayer and Roche and has been a paid expert for Amgen, Bayer and Roche.

MS has received honoraria and research funding from Amgen and has acted as a consultant for Amgen.
GHL has been a PI on a research grant from Amgen to the Duke University in support of the ANC Study Group and has received honoraria from Amgen

EC and TDS have no competing interests.

Received: 16 June 2010 Accepted: 19 August 2010

Published: 19 August 2010

\section{References}

1. Duggan DB, Petroni GR, Johnson JL, Glick JH, Fisher Rl, Connors JM, Canellos JP, Peterson BA: Randomized comparison of ABVD and MOPP/ ABV hybrid for the treatment of advanced Hodgkin's disease: report of an Intergroup trial. J Clin Oncol 2003, 21:607-614.

2. Evens $A M$, Hutchings M, Diehl V: Treatment of Hodgkin lymphoma: the past, present, and future. Nat Clin Pract Oncol 2008, 5:543-556.

3. Raemaekers JMM, van der Maazen RWM: Hodgkin's lymphoma: news from an old disease. Neth J Med 2008, 66:457-466.

4. Kuderer NM, Dale DC, Crawford J, Cosler LE, Lyman GH: Mortality, morbidity, and cost associated with febrile neutropenia in adult cancer patients. Cancer 2006, 106:2258-2266.

5. Aapro MS, Cameron DA, Pettengell R, Bohlius J, Crawford J, Ellis M, Kearney N, Lyman GH, Tjan-Heijnen VC, Walewski J, Weber DC, Zielinski C, European Organisation for Research and Treatment of Cancer (EORTC) Granulocyte Colony-Stimulating Factor (G-CSF) Guidelines Working Party: EORTC guidelines for the use of granulocyte-colony stimulating factor to reduce the incidence of chemotherapy-induced febrile neutropenia in adult patients with lymphomas and solid tumours. Eur J Cancer 2006, 42:2433-2453.

6. Crawford J, Dale JC, Lyman GH: Chemotherapy-induced neutropenia: risks, consequences, and new directions for its management. Cancer 2004, 100:228-237.

7. Chirivella I, Bermejo B, Insa A, Pérez-Fidalgo A, Magro A, Rosello S, GarcíaGarre E, Martín P, Bosch A, Lluch A: Optimal delivery of anthracyclinebased chemotherapy in the adjuvant setting improves outcome of breast cancer patients. Breast Cancer Res Treat 2009, 114:479-484.

8. Bosly A, Bron D, van Hoof A, de Bock R, Berneman Z, Ferrant A, Kaufman L, Dauwe $M$, Verhoef $G$ : Achievement of optimal average relative dose intensity and correlation with survival in diffuse large B-cell lymphoma patients treated with CHOP. Ann Haematol 2008, 87:277-283.

9. Bonadonna G, Valagussa P, Moliterni A, Zambetti M, Brambilla C: Adjuvant cyclophosphamide, methotrexate, and fluorouracil in node-positive breast cancer: the results of 20 years of follow-up. N Engl J Med 1995 332:901-906.

10. Kwak LW, Halpern J, Olshen RA, Horning SJ: Prognostic significance of actual dose intensity in diffuse large-cell lymphoma: results of a treestructured survival analysis. J Clin Oncol 1990, 8:963-977.

11. Lyman $\mathrm{GH}$ : Impact of chemotherapy dose intensity on cancer patient outcomes. J Natl Compr Canc Netw 2009, 7:99-108.

12. Chand VK, Link BK, Ritchie JM, Shannon M, Wooldridge JE: Neutropenia and febrile neutropenia in patients with Hodgkin's lymphoma treated with doxorubicin (Adriamycin), bleomycin, vinblastine and dacarbazine (ABVD) chemotherapy. Leuk Lymphoma 2006, 47:657-663.

13. Crawford J, Dale DC, Kuderer NM, Culakova E, Poniewierski MS, Wolff D, Lyman GH: Risk and timing of neutropenic events in adult cancer patients receiving chemotherapy: the results of a prospective nationwide study of oncology practice. J Natl Compr Canc Netw 2008, 6:109-118.

14. Pettengell $R$, Schwenkglenks $M$, Leonard $R$, Bosly $A$, Paridaens $R$, Constenla M, Szucs T, Jackisch C, Impact of Neutropenia in Chemotherapy European Study Group (INC-EU): Neutropenia occurrence and predictors of reduced chemotherapy delivery: results from the INC-EU prospective observational European neutropenia study. Support Care Cancer 2008, 16:1299-1309.

15. Mosteller RD: Simplified calculation of body-surface area. N Eng J Med 1987, 317:1098.

16. Cancer Therapy Evaluation Program: Common Terminology Criteria for Adverse Events (CTCAE) Version 3.0. 2006 [http://ctep.cancer.gov/ protocolDevelopment/electronic_applications/ctc.htm\#ctc_40], accessed 20 July 2010 . 
17. Dale DC, McCarter GC, Crawford J, Lyman GH: Myelotoxicity and dose intensity of chemotherapy: reporting practices from randomized clinical trials. J Natl Compr Canc Netw 2003, 1:440-454.

18. Evens AM, Cilley J, Ortiz T, Gounder M, Hou N, Rademaker A, Miyata S, Catsaros K, Augustyniak C, Bennett CL, Tallman MS, Variakojis D, Winter JN Gordon LI: G-CSF is not necessary to maintain over $99 \%$ dose-intensity with ABVD in the treatment of Hodgkin lymphoma: low toxicity and excellent outcomes in a 10-year analysis. Br J Haematol 2007, 137:545-552.

19. Boleti $E$, Mead GM: ABVD for Hodgkin's lymphoma: full-dose chemotherapy without dose reductions or growth factors. Ann Oncol 2007, 18:376-380.

20. Chand VK, Link BK, Ritchie JM, Shannon M, Wooldridge JE: Neutropenia and febrile neutropenia in patients with Hodgkin's lymphoma treated with doxorubicin (Adriamycin), bleomycin, vinblastine and dacarbazine (ABVD) chemotherapy. Leuk Lymphoma 2006, 47:657-663.

doi:10.1186/1756-8722-3-27

Cite this article as: Schwenkglenks et al.: Hodgkin lymphoma treatment with ABVD in the US and the EU: neutropenia occurrence and impaired chemotherapy delivery. Journal of Hematology \& Oncology 2010 3:27.

\section{Submit your next manuscript to BioMed Central} and take full advantage of:

- Convenient online submission

- Thorough peer review

- No space constraints or color figure charges

- Immediate publication on acceptance

- Inclusion in PubMed, CAS, Scopus and Google Scholar

- Research which is freely available for redistribution

Submit your manuscript at www.biomedcentral.com/submit 